global process of transforming information to digital form that radically changes the nature of intergroup and interpersonal relationships of people. The conditions of social existence become dependent on digital technologies, which lead to unintended and uncontrollable consequences. The authors attempt to bridge the knowledge gap by turning to the technological discourse of digitalization in order to complement the exclusively sociological discourse. This combination of two distant areas has provided a deeper understanding of the impact of digital technology on public life beyond the interpretation of changes within actor-networking or postmodern terms.

Keywords: digitalization, social digitalization, transformation of sociological profession, methodology of sociology

НАЗАРОВ Михаил Михайлович - доктор политических наук, главный научный сотрудник Института социально-политических исследований РАН (119333, Россия, г. Москва, ул. Фотиевой, 6 , корn. 1; vy175867@yandex.ru)

\title{
ПОЛИТИЧЕСКАЯ КОММУНИКАЦИЯ В ОБЩЕСТВЕ ПОСТПРАВДЫ: ГРАЖДАНЕ И ДОВЕРИЕ К ИНФОРМАЦИОННЫМ ИСТОЧНИКАМ
}

\begin{abstract}
Аннотация. В статье обсуждается доверие к медиа как важная составляющая политической коммуникации в российском обществе. Согласно эмпирическим данным, в целом доверие к медиа является невысоким; граждане склонны не доверять ТВ, прессе, радио в большей степени, нежели Интернету. Доверие к медиа опосредуется отношением к текущей социальной ситуации и политической системе, $к$ ключевым институтам власти, к оценкам результатов деятельности медиа. Автор обосновывает, что размывание доверия к медиа обусловлено как кризисными тенденциями глобального капитализма, так и технологическими и социокультурными трендами современной среды постмодерна.

Ключевые слова: доверие к медиа, политическая коммуникация, постправда, цифровая медиасреда, телевидение, Интернет
\end{abstract}

B рамках данной публикации хотелось бы продолжить обсуждение, которое идет на страницах журнала в связи с проблематикой социально-гуманитарных следствий цифровизации [Лапшин 2019], ее влияния на политические коммуникации в обществе, в т.ч. на доверие к медиа [Дугин 2018]. Понятие доверия в широком смысле трактуется как чувство или убеждение, что какомулибо лицу, обстоятельству можно верить. Доверять - значит полагаться на коголибо, не сомневаться в его честности. В социально-гуманитарной традиции акцент делается на социальной роли доверия как свойства, обеспечивающего функционирование социального организма, снижающего информационную асимметрию в процессе социального взаимодействия.

Исследовательский контекст. Актуальность анализа доверия применительно к сферам политической коммуникации и власти обусловлено тем, что функционирование демократических процессов и широкого общественного участия предполагает наличие информированных граждан, принимающих обоснованные решения. Рассматривая доверие к медиа как некоторое отношение, можно выделить две стороны: тех, кто доверяет, и тех, кому доверяют. Соответственно, в фокусе анализа оказываются те или иные аудитории и информационные источники. В структуре доверия к источникам, как правило, выделяют три основные составляющие. Во-первых, это доверие к медиа - посредникам, каналам, с помощью которых социально-политическая, культурная и прочая информация передается аудитории. Во-вторых, это доверие к собственно источнику, «про- 
вайдеру» этой информации. В-третьих, это доверие к самому сообщению, контенту, т.е. содержанию информационных материалов [Fisher 2018].

Остановимся кратко на прикладных результатах изучения доверия к медиа. В литературе нет единого мнения о том, кто из индивидов в плане их социально-демографической принадлежности в большей степени склонен доверять медиа [Gronke, Cook 2007]. Чем более позитивными являются оценки отдельных медиа (ТВ, радио, пресса), тем более высоким уровнем доверия со стороны аудитории они пользуются. Было также зафиксировано, что большая готовность пользователей делиться информацией в онлайн-сообществе обусловлена большим доверием к онлайн-площадке, на которой это происходит [Cacciatore et al. 2016]. Согласно ряду исследований, большее доверие к медиа проявляют те, кому свойственно активное потребление мейнстримных медиа [Kiousis 2001]. В фокусе исследований также находились вопросы о роли медиа как факторе влияния на составляющие политической культуры. Отмечалось, что доминирование массовых коммерческих медиа способствует распространенности политического цинизма, падению политического доверия граждан [McChesney 1999: 5-7]. Применительно к американскому обществу выявлено, что меньшее доверие к медиа в большей степени присуще индивидам с консервативными ориентациями [Morris 2007]. Существует и другой тренд - более ярко выраженные политические предпочтения и включенность граждан в те или иные виды политической активности предполагают склонность к интерпретации деятельности медиа как необъективной [Lee 2010].

Актуальность исследований доверия к медиа связана также с феноменом постправды. Термин «постправда» широко вошел в политический язык последнего времени. Согласно регулярным оценкам Оксфордского словаря, постправда стала «словом года» в 2016 г. При этом постправда трактуется как некое состояние социальной ситуации, когда объективные факты влияют на общественное мнение в меньшей степени, чем апелляция к эмоциям и личным убеждениям ${ }^{1}$. Данное понятие характеризует новое информационно-политическое состояние общества и непосредственно связно с проблематикой доверия к медиа. Понятие постправды оказалось сейчас атрибутом мирового массового политического дискурса. Выделим несколько обстоятельств, характеризующих контекст его активного использования.

Во-первых, правомерно говорить об общем кризисе мировой экономики и связанных с ним противоречиях в странах Западной Европы, США, субъектов глобального капитализма в целом. Брексит, проблемы миграции, рост поддержки национал-популистских партий и движений во многих европейских странах потребовали объяснений, некоторые из которых предполагали использование новых языковых конструкций. К ним с полным основанием можно отнести понятие постправды. Показательным в этой связи является известный доклад Мюнхенской конференции по безопасности 2017 года с названием «Послеправда, послезапад, послепорядок?» [Munich Security Report 2017]. В документе констатируется, что угрозы современной либеральной демократии исходят от политиков-популистов в западных странах, равно как и от авторитарных режимов, ставящих целью эрозию доверия граждан правительствам и медиа. Причем средством достижения этих целей являются разнообразные инструменты манипулирования информацией, так называемые фейковые новости. Это, в свою очередь, формирует новое состояние постправды, где нет ничего достоверного и все альтернативы являются равновозможными.

\footnotetext{
1 Oxford Dictionaries. 2016. «Word of the Year 2016 Is». URL: https://languages.oup.com/word-ofthe-year/word-of-the-year-2016 (accessed 10.01.2020).
} 
Во-вторых, важным обстоятельством, предопределившим активное использование понятия постправды и сопряженного с ним словосочетания «фейковые новости», является предвыборная президентская кампания в 2016 г. в США и последующее информационное противостояние президента Трампа и так называемых мейнстримных медиа. Впервые за долгие годы противоречия в американском обществе, прежде всего в американских элитных группах, достигли такого уровня напряженности, что это неизбежно проявилось в информационной сфере. Причем роль собственно медиа в этом противостоянии вышла на первый план. Показательным в этой связи является следующее замечание автора американского правоконсервативного издания: «Подозрительно предвзятая позиция медиа - за Клинтон и против Трампа - во время кампании, продолжавших нападки и после инаугурации... - вот причина широкого резонанса фразы Трампа о “фейковых новостях". Американская общественность и раньше замечала, что с основными новостными компаниями ("мейнстримными медиа") что-то не так - но именно выборы 2016 доказали миллионам, насколько прав оказался твит Трампа “Фейковые новостные медиа (плохо работающие @nytimes, @NBCNews, @ABC, @CBS, @CNN) - враг американского народа!”»1.

В-третьих, активное введение в оборот понятия постправды связано с нарастанием противоречий между основными геополитическими акторами. Эпицентром этого является конфликт интересов России и США, политика санкций в отношении нашей страны, новое виток политики «холодной войны».

Результаты эмпирического исследования. Каким является уровень доверия к медиа среди российских граждан? Обратимся к материалам исследования социально-политических настроений, полученных в рамках проекта «Как живет Москва» в Институте социально-политических исследований РАН (см. табл. 1). Эмпирическую основу работы составляют данные репрезентативных исследований населения Москвы, реализованных в мониторинговом режиме в течение двух последних десятилетий. Применялась квотная выборка со связанными параметрами; методом сбора первичной информации являлся самозаполняемый опросник. Общее число опрошенных в 2018 г. $N=726$.

Таблица 1

Доверие к различным источникам информации, в \% от числа опрошенных

\begin{tabular}{|l|c|c|c|c|}
\hline \multicolumn{1}{|c|}{ Источники информации } & Доверяют & $\begin{array}{c}\text { Доверяют } \\
\text { частично }\end{array}$ & Не доверяют & $\begin{array}{c}\text { Затруднились } \\
\text { ответить }\end{array}$ \\
\hline Телевидение & 13,9 & 54,3 & 30,0 & 1,8 \\
\hline Интернет & 14,2 & 61,4 & 18,2 & 6,2 \\
\hline Радио & 9,5 & 47,7 & 28,9 & 13,9 \\
\hline Газеты & 10,5 & 44,5 & 33,9 & 11,1 \\
\hline Журналы & 5,5 & 39,0 & 40,2 & 15,3 \\
\hline $\begin{array}{l}\text { Разговоры с друзьями, } \\
\text { знакомыми }\end{array}$ & 36,8 & 52,3 & 6,0 & 4,9 \\
\hline
\end{tabular}

В связи с приведенными данными выделим несколько важных, на наш взгляд, моментов.

Уровень доверия к медиа - как к традиционным (ТВ, радио, газеты, журналы), так и к новым (Интернет) - в целом является невысоким. Наиболее высоким

\footnotetext{
1 Jasper W.F. Deep State and Fake News. - The New American. 2017. May 8. No. 33. P. 19.
} 
уровнем доверия по сравнению с ними пользуется межличностное общение между людьми. Справедливо и обратное - существенно более высоким является уровень недоверия по отношению к традиционным медиа, а наименьшим - к межличностным каналам коммуникации.

Рассмотрим несколько подробнее характеристики доверия к ТВ и Интернету, которые являются на сегодня наиболее мощными по охвату населения и степени социально-политического влияния медиа. Если доверие к этим медиа является примерно одинаковым, то уровень недоверия к ТВ оказывается большим, чем к Интернету. Представляется, что это отражает общий тренд нарастания значимости Интернета по сравнению с ТВ за последние годы. Согласно нашим наблюдениям, ТВ в течение последних двух десятилетий лидировал при ответах респондентов на вопрос о медиа, которым они доверяли больше всего. Показательно, что в 2017 г. Интернет по уровню доверия обошел ТВ. Несмотря на то что эти данные характеризуют московский регион, они, на наш взгляд, показательны с точки зрения оценки изменения ландшафта политических коммуникаций в целом.

Есть ли особенности доверия к медиа в различных социально-демографических группах? Имеющиеся данные говорят о том, что ТВ чаще доверяют женщины, чем мужчины; наблюдается рост доверия к ТВ с возрастом. Относительная доля лиц, не доверяющих ТВ, оказывается большей в молодых возрастных группах. Представители более молодых возрастных групп чаще доверяют Интернету, чем представители более старшего возраста. В связи с дифференциацией доходов индивидов наблюдается следующий тренд. Лица, принадлежащие к группам с более высоким доходом, чаще доверяют Интернету, чем представители групп с меньшим доходом.

Какие социальные обстоятельства и факторы в максимальной степени влияют на формирование доверия или недоверия к медиа? Применительно к полученным эмпирическим данным нами был использована процедура логистической регрессии. В результате статистического анализа было выявлено несколько групп переменных, повышающих вероятность недоверия к медиа.

Во-первых, недоверие к медиа предопределено тем отношением, которое сложилось у российских граждан к основным государственным и общественным структурам. Согласно нашим исследованиям, динамика доверия в отношении практически всех важнейших институтов является негативной. Так, за период 2016-2018 гг. в полтора-два раза упал уровень доверия к правительству РФ, Совету Федерации, Государственной думе, политическим партиям и движениям, церкви. Падение доверия наблюдалось, хотя несколько в меньшем объеме, в отношении действующего президента РФ.

Во-вторых, недоверие к медиа повышается в связи с отрицательными представлениями людей об окружающей их социальной реальности, например, наличием дорогого и неквалифицированного медицинского обслуживания, наличием преступности и т.п. Недоверие к медиа также оказывается связанным с тем, что респонденты не разделяют положительное отношение к действующей политической системе.

В-третьих, недоверие к медиа соотносится с содержанием установок людей о деятельности средств массовой информации. Так, вероятность недоверия к медиа в большей степени присуща индивидам с негативными представлениями о роли медиа в обществе - тем, кто считает, что нынешние российские медиа формируют искаженные представления о жизни страны и мира, способствуют распространению насилия, разжиганию межнациональной и межрелигиозной розни. Также значимым здесь является индикатор несогласия с оценкой, что медиа повышают уровень культуры и образования людей. 
Таким образом, если граждане удовлетворены основными характеристиками и условиями своего существования, то они скорее всего будут удовлетворены деятельностью основных институтов государства и общества. Соответственно, уровень политического доверия в обществе оказывается выше, когда граждане удовлетворены политикой правительства, что, в свою очередь, распространяется и на доверие к медиа. При этом деятельность медиа являются важным условием повышения информированности граждан, создания адекватных представлений по тем или иным проблемам жизни общества. Таким образом, вне доверия к медиа, по крайней мере в идеале, невозможно функционирование демократических процессов как таковых.

Цифровая среда и новые «координаты» доверия к медиа. Зафиксированный исследованием уровень доверия граждан к российским медиа сопрягается с рядом технологических, политико-экономических и социокультурных трендов, имеющих общецивилизационное измерение. Причем все из них в той или иной мере влияют на сложившиеся ранее практики информационного обмена, включая политические коммуникации, составляя новые условия формирования доверия к медиа.

Важнейшим фактором, влияющим на изменение информационной среды, является прогресс коммуникационных технологий, в частности массовое распространение домашнего и мобильного Интернета. За последнее десятилетие в нашей стране среднесуточное время использования Интернета выросло более чем в 10 раз. Параллельно с этим происходила конвергенция медиа, формирование мультимедийных цифровых платформ, обогащающих коммуникационные возможности. Все это явилось предпосылкой активного использования в повседневных практиках людей социальных сетей (ВКонтакте, Фейсбук и др.), видеохостингов (YouTube), систем быстрого обмена сообщениями - мессенджеров (WhatsApp). Появились цифровые/интернет-версии телевидения, печатных изданий, радио.

Обратим внимание, что новый медиаландшафт предполагает сосуществование двух типов медиа на базе лежащих в их основе коммуникационных моделей. Для офлайновых и онлайновых версий традиционных медиа - ТВ, прессы, радио - преимущественной является модель коммуникации «от одного - многим», где аудитория рассматривается преимущественно в качестве пассивного получателя информации. В современных условиях становится реальностью другая коммуникационная модель - «от многих - многим». Благодаря интерактивным медиа - блогам, социальным сетям, видеохостингам - индивиды могут обращаться к массовым аудиториям, минуя формальные институты массовых медиа.

В итоге произошло увеличение совокупного времени медиапотребления. При этом преобладающая в течение трех-четырех последних десятилетий роль телевидения частично отходит на второй план. Большую часть свободного времени людей в своей совокупности теперь занимает активность в Интернете, прежде всего использование социальных сетей. Однако рост медиапотребления важен не только как таковой - на первый план выходят новые состояния информационной среды, форматы коммуникативного поведения и сопряженные с этим фундаментальные социальные тренды.

В этой связи надо сказать о текущей мировой и российской ситуации, условно - на макроуровне. Трудно отрицать тот факт, что в последние годы мы ощущаем изменения, зачастую кризисного порядка, в том, что принято называть духовным климатом эпохи. Очевидно, что это имеет предпосылки в логике развития современного капитализма на глобальном уровне, с одной стороны, и на национальном, российском уровне - с другой. Причем это проявляется в самых раз- 
ных областях - от геополитической до социокультурной. Особенности нынешнего социального времени часто описывают с помощью понятия «постмодерн». Последнее имеет целый ряд характеристик. Выделим те из них, которые имеют прямое отношение к проблематике доверия к медиа.

В условиях постмодерна политико-экономические и социокультурные процессы становятся во все большей степени конструируемыми. Роль медиа в создании и интерпретации «картин мира» трудно переоценить. Более того, отмечавшиеся выше технологические факторы и рост медиапотребления объективно приводят к тому, что рост образных посредников при формировании социального опыта людей неуклонно возрастает. Среда бытования современного человека становится все более искусственной. Медийные технологии позволяют создавать материалы, где события выглядят абсолютно реальными (при этом в действительности такие события не происходили) [Назаров 2018: 20-23]. Соответственно, это объективно затрудняет ориентацию людей в усложнившемся информационном поле, препятствует формированию доверия к медиа.

Как представляется, упомянутый выше феномен постправды и проблематика так называемых фейковых новостей отражает, среди прочего, следующее обстоятельство. Происходит изменение сложившегося в течение нескольких последних десятилетий (по крайней мере, в так называемых индустриально развитых странах) либерально-демократического информационного порядка. В рамках политического консенсуса элит массовая политическая информация циркулировала в коммуникационном пространстве, формируемом телевидением, прессой и радио, и была направлена в целом на подержание статус-кво. При всем разнообразии этих средств можно было говорить о том, что именно мейнстримные медиа эффективно выполняли функции gatekeepers, т.е. регулирования, или фильтрации доступа к тому, что будет находиться в информационном пространстве, т.е. в сфере общественного внимания. Применительно к новостной журналистике и редакционной политике медиа это выражалось в принятии стратегических решений о достоверности и качестве используемых источников. Важным, зачастую неявным фактором в этой связи является соотнесение отбора с доминирующими политическими ценностями, соответствие их принятым нормам и конвенциям ${ }^{1}$. Так, формировалось пространство диалога, дискуссий и конкуренции для согласования интересов различных групп. В условиях общего роста недоверия к институтам власти и параллельно с кардинальным расширением числа доступных информационных источников появились широкие возможности выражения альтернативных точек зрения, в т.ч. имеющих несистемный характер. Это изменение информационного порядка так или иначе усложнило основания выбора и вынесение суждений о доверии к медиа.

Бурный рост числа источников и объемов информации, доступной для аудитории, способствует распространению так называемого информационного переполнения [Andrejevic 2013: 9-10]. Усиление конкуренции между медиа приводит к тому, что форматы контента в целом становятся более короткими - с преобладанием эмоционально насыщенных форматов. Цель состоит в том, чтобы привлечь аудиторию за более короткий, чем ранее, интервал времени. Это тем более так, поскольку подавляющее большинство ведущих медиа как в нашей стране, так и за рубежом являются также субъектами бизнеса и значимо зависят от рекламных поступлений. Таким образом, уменьшается доля

\footnotetext{
${ }^{1}$ Chandler D., Munday R. 2014. A Dictionary of Media and Communication. Oxford: Oxford University Press. P. 166.
} 
содержания (особенно в сегменте общественно-политической проблематики), предполагающего линейное - последовательное - восприятие, опирающееся на причинно-следственные связи как необходимый элемент рационального осмысления событий и явлений. Как следствие, меняются сложившиеся ранее практики коммуникативного поведения, происходит упрощение моделей восприятия, в т.ч. отношения к медиа, оснований для формирования доверия к ним.

Заметим, что трансформация медийного контента отражает ряд содержательных особенностей постмодерна как культурной формы - состояние неопределенности, ценностного релятивизма, абсурда, в пределе - хаоса, которые оказываются доминирующими в культуре и бытии людей, причем как на массовом, так и на элитном уровне. На поддержание этого работают ТВ и Интернет, представляющие собой архетипические постмодернистские культурные формы, поскольку в их содержании ярко проявляются такие черты, как мозаичность, фрагментарность сообщений и повествований, самореференция (отсылка не к реальности, а к другому материалу медиа), акцент на форме представления, а не на содержании.

Не будем также забывать, что информационная среда всегда была ареной конкуренции не только между коммерческими, но и собственно политическими субъектами. Это, среди прочего, достигается с помощью гуманитарных технологий, где ресурс доверия играет важную роль. При этом уместной, как представляется, является отсылка к теореме Томаса - важной познавательной составляющей социологического конструктивизма. В ней утверждается, что ситуация, определенная людьми как реальная, оказывается реальной по своим последствиям. Актуальность этого утверждения определяется тем, что в условиях постмодерна все большую роль играют такие явления, как информационные войны, институты «мягкой силы» и т.П. Их деятельность зачастую предполагает формирование коммуникационной обстановки, когда объективные основания для вынесения гражданами тех или иных суждений оказываются подмененными «спектаклем», некой фиктивной реальностью. Более того, никуда не уходит вопрос о корпоративной принадлежности информационных источников крупнейшим медиагруппам и, соответственно, субъектам бизнеса и власти. Поэтому представления о роли средств массовой коммуникации как «четвертой власти» и наделение их функциями систематического общественного контроля за находящимися у власти и объективного информирования о деятельности последних имеют все более «потенциальный» характер.

Здесь также стоит напомнить известную идею Маклюэна, что тип используемого медиа во многом определяет его содержание [Маклюен 2003: 9-11]. Это напрямую относится к вопросу об усложнении формирования доверия к медиа в условиях массового распространения Интернета и социальных сетей. При всех несомненных достоинствах социальных медиа у них имеются свойства, которые неоднозначно сказываются на формировании доверия в обществе, в т.ч. доверия к медиа. Архетипичность социальных сетей как постмодернистской формы проявляется в преобладающем здесь типе дискурса. Исследователи в этой связи говорят, что логика общественных дискуссий в целом трансформируется под влиянием «языка» обсуждений в социальных медиа. Применительно к последним президентским выборам в США социальные медиа стали пространством для объединения тех групп, которые выступали против «либеральной ортодоксии и тирании политкорректности». При этом Твиттер как один из эффективных инструментов коммуникации этих групп в силу своей технологической природы (не более 140 знаков для послания) далеко не всегда предполагает какую-либо рациональную дискуссию. 
Напротив, распространенным типом общения оппонентов здесь становится троллинг. Изначально это была форма сетевой коммуникации, когда пользователь, как правило анонимно, мог оставить комментарий с целью уязвить, шокировать, обидеть оппонента. Постепенно провокации и издевательства в сетевом общении стали массовым явлением. Более того, это стало нормой, в т.ч. в сфере политических коммуникаций с использованием социальных сетей. При этом одной из целей подобных действий является обеспечение максимально возможной популярности, а не обеспечение обоснованности, аргументированности тех или иных посылок. В этих условиях тема доверия в коммуникации просто не стоит. Причем есть все основания говорить, что здесь самым ярким образом проявляется такая черта культуры постмодерна (в т.ч. политической культуры), как доведенная до абсурда ирония или «стеб» - сарказм и уничижительное осмеивание субъекта в его присутствии.

Сделаем еще одно замечание об экономико-технологических особенностях Интернета, которые влияют на формирование доверия. Цифровые технологии открывают дополнительные возможности для адресного обращения к целевым аудиториям. Основу этого составляет маркетинг на основе баз данных о потребителях и соответствующие технологические алгоритмы. Здесь используется то обстоятельство, что в интернет-среде все более заметными, прозрачными, «гласными» становятся действия индивидов. «Человеческое общение... с помощью цифровых устройств оставляет след: любой щелчок мышки, наведение курсора, переход по ссылке, комментарий и даже включение телефона - все это фиксируется, составляя “большие данные”, так что правильный сбор и обработка этой информации позволяет делать выводы о потребителе» [Warncke 2012]. Благодаря технологиям таргетирования и поисковых алгоритмов в Интернете становится возможным создавать и постоянно поддерживать для пользователя информационную среду, которая строится на основе анализа его предыдущих интересов и действий. Причем это касается не только сферы покупок товаров и услуг, но и собственно информации, в т.ч. политико-идеологического и культурного порядка.

Фактически предиктивные алгоритмические подходы к отбору информации оставляют в стороне вопрос, что медиа выполняют в обществе важные социальные функции. Использование гражданами надежных информационных источников является одной из предпосылок конструктивного обсуждения и социально ответственных решений. Алгоритмизация прежде всего ориентируется на рыночную логику успеха - обеспечение растущего трафика пользователей и, соответственно, финансовой устойчивости и успешности медиа. Показательно, что ряд исследователей указывают на то, что доминирующие ныне технологоэкономические практики Интернета способствует «погружению» пользователя в так называемый фильтрующий пузырь (filter bubble). Речь идет о том, что вольно или невольно пользователю предлагаются ссылки на публикации и источники, где отсутствуют альтернативные взгляды. Фактически это результат одновременной работы большого числа предиктивных алгоритмов, которые «стирают» из поля информационного внимания пользователя идеи и оценки, противоречащие его мировоззрению [Pariser 2011].

Заключение. Итак, в работе показано, что доверие к медиа в российском обществе испытывает вызовы различной природы. С одной стороны, это обусловлено текущими политико-культурными и социально-экономическими трендами в нашей стране. Согласно проведенным исследованиям, доверие к медиа является невысоким; жители столичного мегаполиса склонны не доверять ТВ, прессе, радио в большей степени, нежели Интернету. Доверие к медиа опосредуется отношением к текущей социальной ситуации и политической системе, 
к ключевым институтам власти, к оценкам результатов деятельности медиа. С другой стороны, текущие трансформации общецивилизационного плана создают новые координаты для формирования доверия к медиа. К ним относятся кардинальные технологические изменения в сфере коммуникаций, увеличение уровня конструируемости «картин мира» в условиях политико-экономической и социокультурной среды постмодерна, изменение глобального либерального информационного порядка, доминирование экономического императива в деятельности медиа и размывание роли медиа как «четвертой власти», трансформация рациональных дискурсивных практик и алгоритмизация как фундаментальные черты современной цифровой интернет-среды. Понимание и учет этих обстоятельств может способствовать совершенствованию социального управления, равно как формированию полноценной политической коммуникации в российском обществе в целом.

\section{Список литературы}

Дугин Е.Я. 2018. Власть доверия и доверие власти. - Власть. Т. 26. № 8. С. 60-66.

Лапшин А.О. 2019. Глобализация и цифровое общество: заметки на полях. Власть. Т. 27. № 1. С. 63-68.

Маклюен М. 2003. Понимание медиа: Внешние расширения человека. М.: Канон Пресс. 464 c.

Назаров М.М. 2018. Массовая коммуникация и общество. Введение в теорию и исследования. М.: Ленанд. 378 с.

Andrejevic M. 2013. Infoglut: How Too Much Information Is Changing the Way We Think and Know. N.Y.: Routledge. 174 p.

Cacciatore M., Menga J., Boyd B., Reber B. 2016. Political Ideology, Media-Source

Preferences, and Messaging Strategies: A Global Perspective on Trust Building. Public Relations Review. Vol. 42. Is. 4. P. 616-626.

Fisher K. 2018. What Is Meant by 'Trust' in News Media? - Trust in Media and Journalism. Empirical Perspectives on Ethics, Norms, Impacts and Populism in Europe (ed. by K. Otto, A. Kohler). Springer VS. P. 19-38.

Gronke P., Cook T.E. 2007. Disdaining the Media: The American Public's Changing Attitudes toward the News. - Political Communication. Vol. 24. P. 259-281.

Kiousis S. 2001. Public Trust or Mistrust? Perceptions of Media Credibility in the Information Age. - Mass Communication \& Society. Vol. 4. No. 4. P. 381-403.

Lee T. 2010. Why They Don't Trust the Media: An Examination of Factors Predicting Trust. - American Behavioral Scientist. Vol. 54. P. 18-21.

McChesney R. 1999. Rich Media, Poor Democracy. Communication Politics in Dubious Times. N.Y.: The New Press. 427 p.

Morris J. 2007. Slanted Objectivity? Perceived Media Bias, Cable News Exposure, and Political Attitudes. - Social Science Quarterly. Vol. 88. No. 3. P. 707-728.

Munich Security Report. Post-Truth, Post-West, Post-Order? 2017. URL: https:// www.securityconference.de/en/publications/munich-security-report/munich-security-report-2017 (проверено 10.01.2020).

Pariser E. 2011. The Filter Bubble. What The Internet Is Hiding from You. London: Penguin. 203 p.

Warncke C. 2012. Big Data Strategies: Key Themes from I-COM 2012. Event Reports. URL: https://www.warc.com/content/paywall/article/event-reports/big-data-strategies-key-themes-from-i-com-2012/98228 (проверено 15.01.2020). 
NAZAROV Mikhail Mikhailovich, Dr.Sci. (Pol.Sci.), Chief Researcher of the Institute for Social and Political Studies, Russian Academy of Sciences (bld. 1, 6 Fotievoj St, Moscow, Russia, 119333; vy175867@ yandex.ru)

\section{POLITICAL COMMUNICATIONS IN THE POST-TRUTH SOCIETY: CITIZENS AND TRUST IN INFORMATION SOURCES}

Abstract. The article considers trust in media as an important issue of political communication in Russian society. The author provides empirical evidence that trust in media is low. Citizens tend to distrust TV, the press, and radio more than the Internet. The most reliable source of information is interpersonal communication. The research results confirmed that trust in Russian media is determined by a number of factors: attitude to socio-economic problems; trust in key power institutions and the political system as a whole; evaluations of media social functions performance. The author argues that current transformations of global capitalism bring additional complexities for media trust building. These include: fundamental technological changes in the field of communications; an increase in the level of constructability of "pictures of the world" in conditions of a postmodern political-economic and socio-cultural environment; changing global liberal information order; the dominance of the economic imperative in media activities and the erosion of the role of media as the "fourth power»; transformation of rational discursive practices and introduction of search algorithms as fundamental features of the digital Internet environment.

Keywords: trust in media, political communications, post-truth, digital media, television, Internet

КЛЯГИН Сергей Вячеславович - доктор философских наук, профессор; заведующий кафедрой теории и практики общественных связей Российского государственного гуманитарного университета (125993, Россия, г. Москва, ГСП-3, Миусская пл., 6; sklyagin@gmail.com); профессор департамента социологии, философии и истории Финансового университета при Правительстве РФ (125167, Россия, г. Москва, Ленинградский пр-кт, 49; SVKlyagin@fa.ru)

ПЕРЕМИБЕДА Павел Александрович - кандидат социологических наук, доцент департамента социологии, философии и истории Финансового университета при Правительстве РФ (125167, Россия, г. Москва, Ленинградский пр-кт, 49; PAPeremibeda@fa.ru)

\section{НЕПОЛИТИЧЕСКИЕ РЕСУРСЫ ПОЛИТИЧЕСКОГО: О ДИНАМИЧЕСКИХ МОДЕЛЯХ В МЕТОДОЛОГИИ ИЗУЧЕНИЯ И РЕАЛИЗАЦИИ МЕЖКУЛЬТУРНОЙ КОММУНИКАЦИИ}

Аннотация. В статье рассматриваются неполитические (социальные и социально-культурные) предпосылки для создания новых возможностей в политической сфере информационно-коммуникативного социума. В качестве средства реализации этих возможностей предлагаются динамические модели, которые используются в методологии изучения и реализации межкультурной коммуникации.

Ключевые слова: политика, коммуникация, культура, методология

И зменения общественных процессов в информационно-коммуникативном социуме находят выражение в политической сфере общества. Независимо от концептуальных контекстов в трактовках политических явлений влияние на социум новейших трансформационных факторов проявляется, прежде всего, в 